\title{
Stability ANd Compatibility OF DRUg MixtURES from Intrathecal Pump Using High Performance Liquid Chromatography
}

\author{
Saba Javed, MD, and Billy K. Huh, MD, PhD
}

Although management of intractable pain using long-term intrathecal analgesic administration by implantable infusion systems has become acceptable clinical practice, this method presents unique challenges regarding the stability of the pharmaceutical agent(s) delivered. The stability and compatibility of a single drug such as hydromorphone or bupivacaine, as well as mixtures of morphine-clonidine, have previously been reported, but only using implantable infusion systems and syringes under simulated clinical use conditions, not from implanted intrathecal pumps. The objective of this study was to assess the compatibility and stability of drug mixtures from intrathecal pumps placed in patients.

For this case-series, 5 patients with intrathecal pumps who presented to the pain clinic for refill were randomly selected. An aliquot of sample extracted from the pump and an aliquot of new medicine used for pump refill were collected. High performance liquid chromatography (HPLC) was used to compare the 2 samples.

Drug samples used were as follows: $(A)$ hydromorphone only, (B) morphine and bupivacaine, (C) hydromorphone and ziconotide, (D) ziconotide and baclofen; and (E) hydromorphone, ziconotide, and baclofen. Samples B and E ap- peared to be stable when placed in situ in the SynchroMed II intrathecal pump based on the HPLC analysis. However, samples A, C, and D appeared to have undergone some degradation and/or byproduct formation as noted in the graphical display on HPLC.

While sample A was a single-drug combination, the sample was in the pump for over 3 months; likewise, sample E was a 3-drug combination, however it was in the pump for only 30 days. Based on these results, it appears as though (a) when the length of time the drug stays in the intrathecal pump increases, or (b) when a combination of drugs is used in the intrathecal pump (as opposed to a single drug), some drug degradation and/or byproduct formation happens as seen on HPLC.

This is the first reported study assessing the compatibility and stability of drug mixtures from intrathecal pumps. While the above reported HPLC data reveals quantitative differences, further qualitative analysis is required for confirmation and possible identification of possible degradation and/or byproducts.

Key words: Degradation, high performance liquid chromatography, intrathecal pump
From : University of Texas MD Anderson Cancer Center, Houston, TX

Author for correspondence: Saba Javed, MD

Address: University of Texas MD Anderson Cancer Center, 1515 Holcombe Blvd., Houston, TX 77030

E-mail: sabajaved23@gmail.com

Disclaimer: There was no external funding in the preparation of this manuscript. Conflict of interest: Each author certifies that he or she, or a member of his or her immediate family, has no commercial association (i.e., consultancies, stock ownership, equity interest, patent/licensing arrangements, etc.) that might pose a conflict of interest in connection with the submitted manuscript.
The continuous infusion of drugs by intrathecal route is used for the treatment of chronic pain that has not responded to simpler measures. Analgesic drugs, such as opioids, administered intrathecally with an implantable infusion pump, produce a potent analgesic effect via central nervous system opioid receptors; and the use of these drugs is increasing. A number of drugs have been shown to produce analgesic effects intrathecally including morphine, ziconotide, hydromorphone, meperidine, fentanyl, sufen- 
tanil, clonidine, and bupiviciane $(1,2)$. The intrathecal administration of drug combinations on a continuous basis from an implantation pump has become a frequent practice. The stability and compatibility of a single drug such as hydromorphone or bupivacaine, as well as mixtures of morphine-clonidine, have previously been reported using implantable infusion systems and syringes under simulated clinical use conditions $(3,4)$. The goal of this study was to assess the safety and compatibility of drug mixtures in the intrathecal pump by comparing the drug mixture that was initially placed in the intrathecal pump to the drug mixture that was extracted from the pump using high performance liquid chromatography (HPLC). Herein, we analyzed single drug, 2-drug, and 3-drug combinations to assess the stability and compatibility of drug mixtures using HPLC.

\section{METHOD}

HPLC is a technique used in analytical chemistry to separate and quantify components in a mixture. In brief, the solvent (mobile phase) passes through the solvent delivery system and "picks up" the sample carrying it over to the HPLC column, where it is separated based on the molecular weight and polarity of the chemical structure. The detector subsequently collects this data and plots it on a chromatogram. HPLC was used as the assessment tool to analyze each drug mixture. These samples of drug mixtures were collected from patients who presented to the Pain Management Center at the MD Anderson Cancer Center for their scheduled intrathecal pump refill. Patients were selected at random and informed consent obtained. Prior to the refill with the new drug mixture, the remaining drug mixture from the intrathecal pump (SynchroMed II, Metronic, Minneapolis, MN) was extracted and a $2 \mathrm{~mL}$-aliquot was collected in a 5-mL clear glass ampule. Likewise, a $2 \mathrm{~mL}$-aliquot of the new drug mixture (used to refill the intrathecal pump) was collected in a 5-mL clear glass ampule. Each sample was labeled with appropriate identifiers in accordance with the Health Insurance Portability and Accountability Act (HIPAA). These samples were analyzed using HPLC.

HPCL was performed using a quaternary gradient pump P1000XR Spectra System (Thermo Fischer Scientific, Waltham, MA) with a $100-\mu \mathrm{L}$ fixed volume injector (Thermoquest, Les Ulis, France) coupled to an auto-injector (AS 3000 Spectra System, (Thermo Fischer Scientific, Waltham, MA) and a photodiode array-detector (Spectra System 6000 LP, (Thermo Fischer Scientific, Waltham, MA)), with a fixed wavelength set at $200 \mathrm{~nm}$. The Thermoquest Chromquest software (Thermo Fischer Scientific, Waltham, MA) was used for system control, data acquisition, and process. The separation column $(250 \mathrm{~mm} \times 4.6 \mathrm{~mm}$ inner diameter [I.D.] was a 5- $\mu \mathrm{m}$ Hypurity C18 (ThermoHypersil, (Thermo Fischer Scientific, Waltham, MA) maintained at $35^{\circ} \mathrm{C}$. The device was completed with a precolumn $(\mathrm{C} 18,5 \mu \mathrm{m}, 4 \mathrm{~mm} \times 4.4 \mathrm{~mm}$ I.D., ThermoHypersil). Elution was performed with a mobile phase constituted with acetonitrile $40 \%$ and phosphate buffer with heptane sulfonic acid $60 \%$ (pH 3.8). The mobile phase was used at a constant flow rate of $1.0 \mathrm{~mL}$ per minute. The sample injection volume was $10 \mu \mathrm{L}$. Each drug sample was analyzed individually with retention times as follows: ziconotide 0.58 seconds, morphine 0.66 seconds, bupivacaine 0.67 seconds, hydromorphone 0.98 seconds, and baclofen 1.9 seconds.

\section{RESULTS}

Drug mixtures for the samples used in the study are listed in Table 1. Sample A: hydromorphone $(7.5 \mathrm{mg} / \mathrm{mL})$, sample B: morphine $(10 \mathrm{mg} / \mathrm{mL})$ and bupivacaine $(5 \mathrm{mg} / \mathrm{mL})$, sample C: ziconotide (20 $\mathrm{mcg} / \mathrm{mL}$ ) and hydromorphone $(7.5 \mathrm{mg} / \mathrm{mL})$, sample D: ziconotide $(20 \mathrm{mcg} / \mathrm{mL})$ and baclofen $(1000 \mathrm{mcg} /$ $\mathrm{mL})$, and sample $\mathrm{E}$ : ziconotide $(20 \mathrm{mcg} / \mathrm{mL})$, hydromorphone $(7.5 \mathrm{mg} / \mathrm{mL})$, and baclofen $(1000 \mathrm{mcg} /$ $\mathrm{mL}$ ). Visual comparison of the samples is depicted in Fig. 1. For samples A, B, D, and $E$ (not pictured), both the sample of drug mixture extracted from the pump and the new drug mixture were clear fluids. The sample $C$ drug mixture that was extracted from the intrathecal pump had a yellow-tinged discoloration when compared to the sample $\mathrm{C}$ new drug mixture.

All of the samples were analyzed using HPLC. Figure 2 (inset) displays the HPLC analysis of the sample A new drug used to refill the pump. Retention time for hydromorphone is shown at 1.0 second, along with peaks at 0.37 seconds and 0.58 seconds, likely from the solvent $(0.9 \%$ normal saline) the sample was dissolved in. The black asterisk $\left({ }^{*}\right)$ points to the 


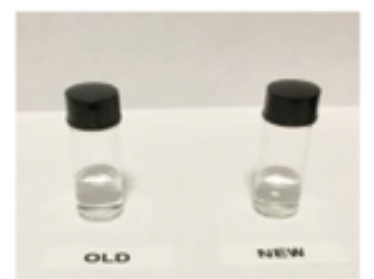

Sample A. Hydromorphone (7.5 mg/mL)

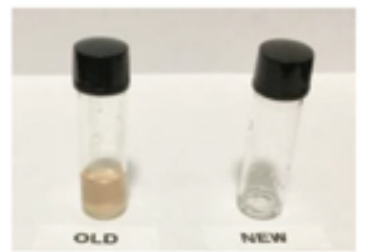

Sample C. Ziconotide (20

$\mathrm{mcg} / \mathrm{mL}) /$ hydromorphone $(7.5 \mathrm{mg} / \mathrm{ml})$

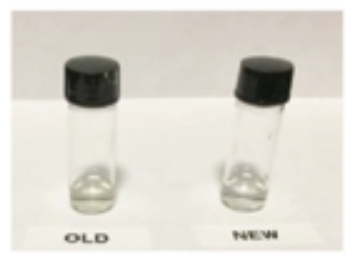

Sample B. Morphine (10 $\mathrm{mg} / \mathrm{ml}) /$ bupivicaine $(5 \mathrm{mg} / \mathrm{mL})$

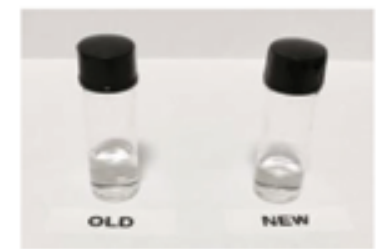

Sample D. Ziconotide $(20 \mathrm{mcg} / \mathrm{mL}) / \mathrm{baclofen}(1000 \mathrm{mcg} / \mathrm{mL})$

Fig. 1. Comparison of the sample extracted from the intrathecal pump (labeled as "old") and the new sample of drug mixture placed in the pump (labeled as "new").

peaks that were not present in the new sample, likely an impurity or a degradation product. These peaks are presented at retention times of 1.8 and 2.6 seconds.

The HPLC graphical analysis of sample B is represented by a single broad peak at 0.69 seconds for both the drug mixture that was extracted and the new sample that was refilled in the pump. Figure 3 displays the HPLC of sample C. The graph displays retention times for ziconotide and hydromorphone as shown at 0.58 and 1.0 seconds, respectively. An additional peak at 2.09 seconds was visible in the sample that was extracted from the intrathecal pump, again presumptively an impurity or byproduct that was not seen in the original sample.

Figure 4 displays the HPLC analysis of sample D. The graph displays retention times for ziconotide and baclofen as shown at 0.56 and 1.9 seconds, respectively. Additional peaks at $0.46,0.71,2.5$, and 5.7 seconds were visible in the sample of drug mixture that was extracted from the intrathecal pump,
Table 1. Various drug mixtures samples in the intrathecal pump.

\begin{tabular}{|l|c|c|}
\hline & Drug mixtures & $\begin{array}{c}\text { Frequency of } \\
\text { pump refill }\end{array}$ \\
\hline Sample A & Hydromorphone $(7.5 \mathrm{mg} / \mathrm{mL})$ & 80 days \\
\hline Sample B & $\begin{array}{c}\text { Morphine }(10 \mathrm{mg} / \mathrm{mL}) / \text { Bupivicaine } \\
(5 \mathrm{mg} / \mathrm{mL})\end{array}$ & 60 days \\
\hline Sample C & $\begin{array}{c}\text { Ziconotide }(20 \mathrm{mcg} / \mathrm{mL}) / \\
\text { Hydrodmorphone }(7.5 \mathrm{mg} / \mathrm{mL})\end{array}$ & 90 days \\
\hline Sample D & $\begin{array}{c}\text { Ziconotide }(20 \mathrm{mcg} / \mathrm{mL}) / \mathrm{Baclofen} \\
(1000 \mathrm{mcg} / \mathrm{mL})\end{array}$ & 60 days \\
\hline Sample E & $\begin{array}{c}\text { Ziconotide }(20 \mathrm{mcg} / \mathrm{mL}) / \\
\text { Hydromorphone }(7.5 \mathrm{mg} / \mathrm{mL}) / \\
\text { Baclofen }(1000 \mathrm{mcg} / \mathrm{mL})\end{array}$ & 30 days \\
\hline
\end{tabular}

again presumptively an impurity or byproduct. Lastly, the sample $E$ drug mixture, which was comprised of ziconotide, hydromorphone, and baclofen, have peaks at $0.58,0.92$, and 1.97 seconds in both the sample that was extracted from the pump and the new sample that was used to refill the pump. 


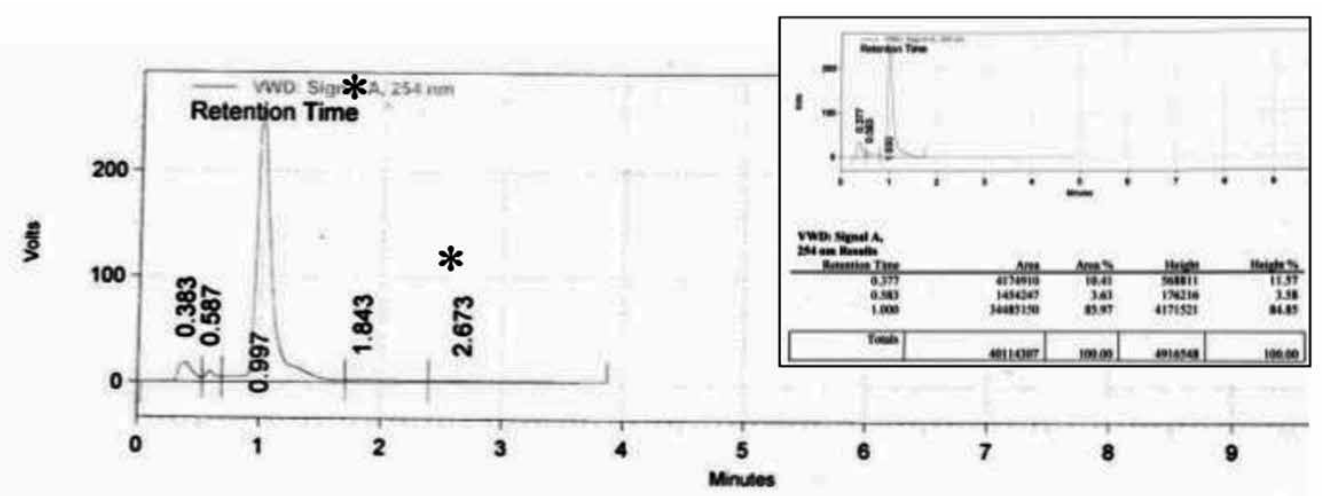

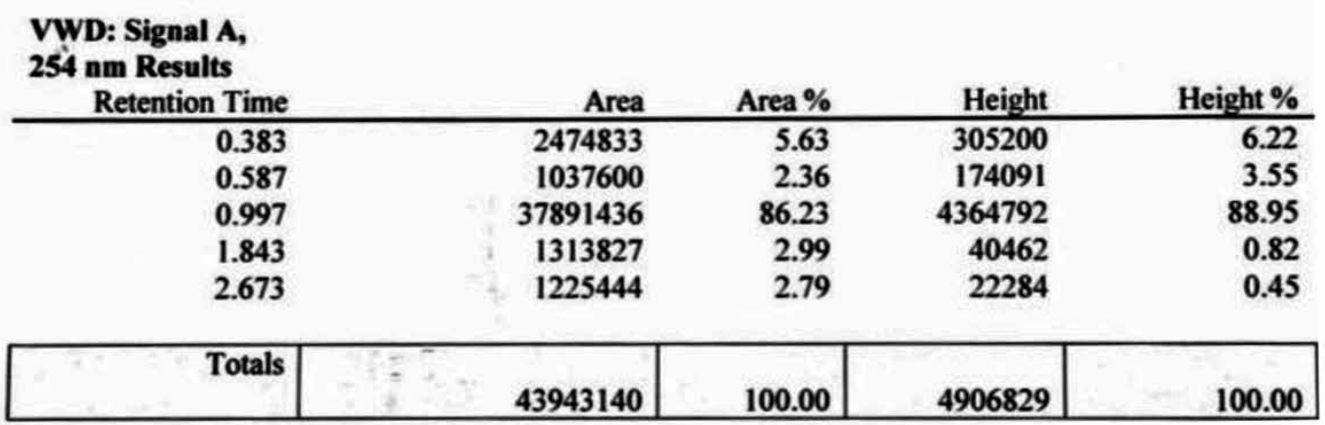

Fig. 2. HPLC of Sample A, which was extracted from the pump. Black asterisk $(*)$ points to the new peaks that were not present in the new sample. Inset: HLPC of the new drug mixture that was placed in the pump.
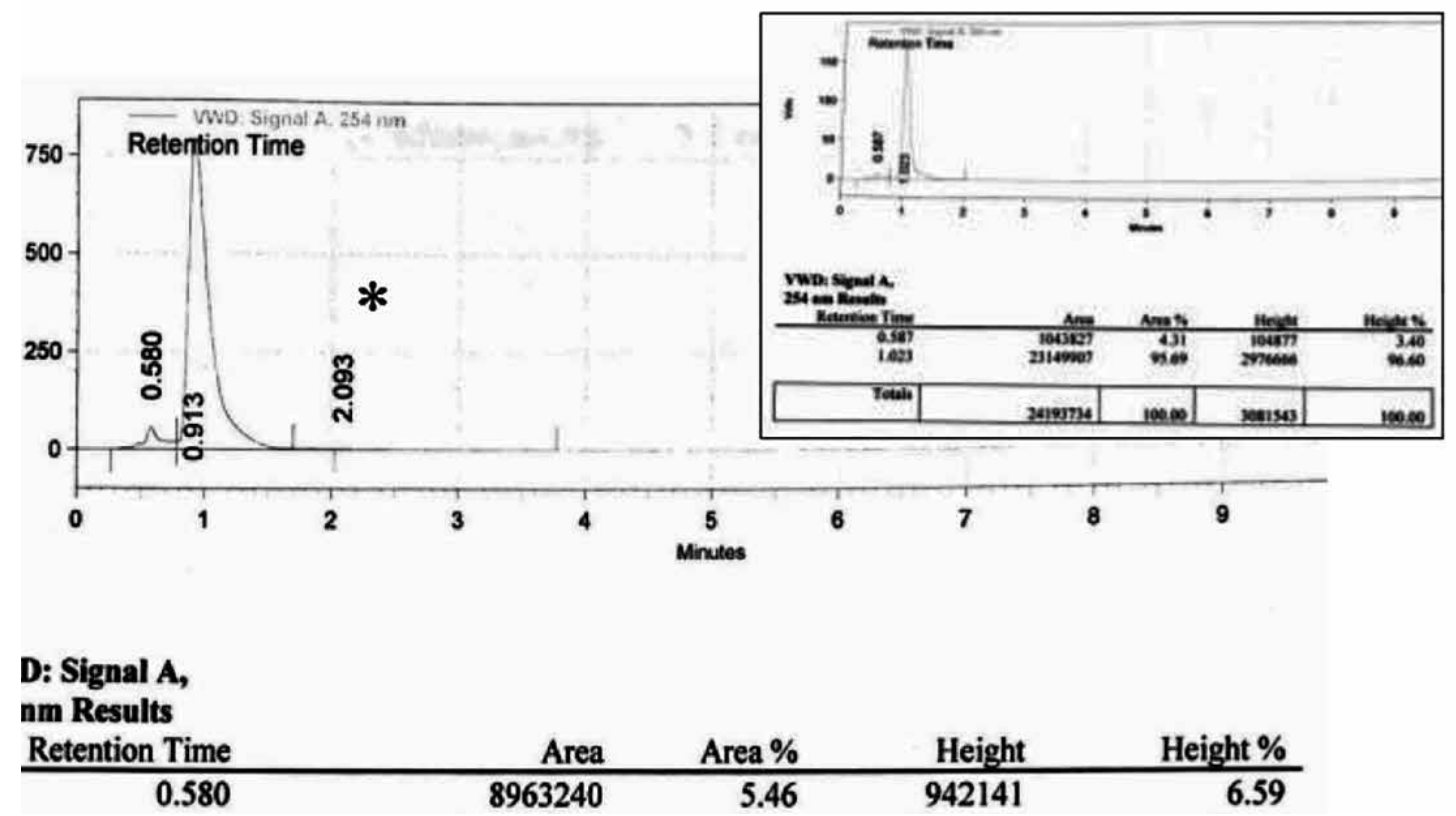

Fig. 3. HPLC of Sample C, which was extracted from the pump. Black asterisk $(*)$ points to the new peaks that were not present in the new sample. Inset: HLPC of the new drug mixture that was placed in the pump. 


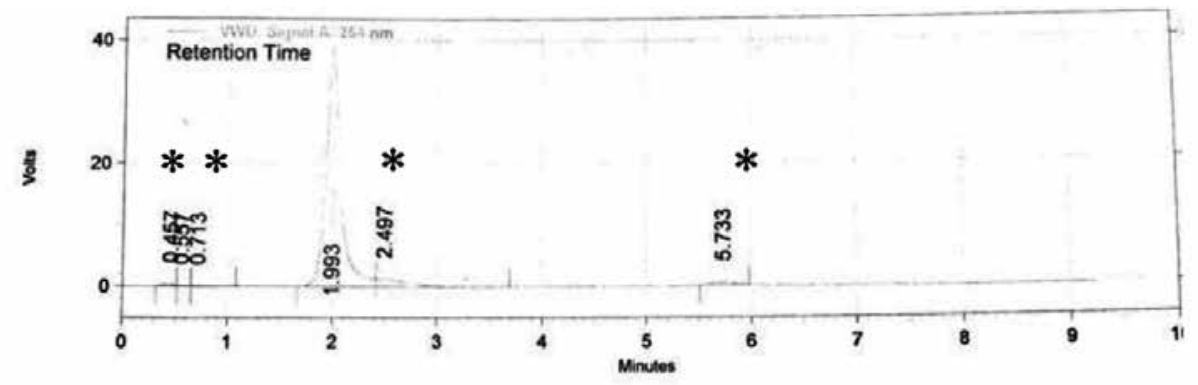

\begin{tabular}{|c|c|c|c|c|}
\hline $\begin{array}{l}\text { VWD: Signal A, } \\
254 \text { nm Results } \\
\text { Retention Time }\end{array}$ & Area & Area \% & Height & Height $\%$ \\
\hline 0.457 & 40787 & 0.59 & 5941 & 0.86 \\
\hline 0.557 & 7511 & 0.11 & 1308 & 0.19 \\
\hline 0.713 & 9164 & 0.13 & 940 & 0.14 \\
\hline 1.993 & 6293105 & 91.58 & 650403 & 94.66 \\
\hline 2.497 & 402665 & 5.86 & 20714 & 3.01 \\
\hline 5.733 & 118490 & 1.72 & 7802 & 1.14 \\
\hline Totals & & & & \\
\hline & 6871722 & 100.00 & 687108 & 100.00 \\
\hline
\end{tabular}

Fig. 4. HPLC of Sample D, which was extracted from the pump. Black asterisk $(*)$ points to the new peaks that were not present in the new sample.

\section{DISCUSSION}

Although management of intractable pain using long-term intrathecal analgesic administration by implantable infusion systems has become acceptable clinical practice, this method presents unique challenges regarding the stability of the pharmaceutical agent(s) delivered. Currently, the drugs approved by the US Food and Drug Administration (FDA) for intrathecal use are as follows: morphine, baclofen, and ziconotide. Morphine remains the gold standard in analgesia for intense pain and suffering. Like all opioids, morphine binds to the opioid receptor family in the central nervous system. Local anesthetics such as ropivacaine or bupivacaine are used to potentiate the effects of morphine by blocking nervous conduction in the sodium channels. Ziconotide acts as a selective $\mathrm{N}$-type voltage-gated calcium channel blocker. Ziconotide used in low concentrations in combination with morphine and bupivacaine seems to be very useful and to have an acceptable tolerance compared to high doses of morphine (5). Previous studies have examined the compatibility and stability of drug mixtures in implantable pumps and syringes under simulated clinical use conditions (5). Nevertheless, the compatibility and stability of drug mixtures from implantable pumps (in situ) in humans have not been assessed before. The goal of this study was to assess if the drug mixture initially placed in the intrathecal pump was identical in nature to the drug mixture that was extracted from the pump.

There was no obvious visual difference in any of the samples between the drug mixture extracted from the pump compared to the new drug mixture, except for sample $C$ (Fig. 1). Comprised of ziconotide $(20 \mathrm{mcg} / \mathrm{mL})$ and hydromorphone $(7.5 \mathrm{mg} / \mathrm{mL})$, this drug mixture appeared to have a yellow-tinged discoloration in the sample that was taken out of the pump. None of the samples had any impurities or solid particulates present.

As noted, HPLC was used to process and analyze each sample. As seen in Figs. 2-4, samples A, C, and $D$ were found to have additional peaks on the HPLC in the sample that was extracted from the pump when compared to the sample that was used to refill the intrathecal pump. These additional peaks are presumably due to drug degradation and/or byproduct, as they were not present in the sample initially. Sample A was not a drug mixture, but was simply 
hydromorphone $7.5 \mathrm{mg} / \mathrm{mL}$; however, the sample was in the intrathecal pump for 80 days. Sample C was a drug mixture of ziconotide $(20 \mathrm{mcg} / \mathrm{mL})$ and hydromorphone $(7.5 \mathrm{mg} / \mathrm{mL})$, whereas, sample D was a mixture of ziconotide $(20 \mathrm{mcg} / \mathrm{mL})$ and baclofen $(1000 \mathrm{mcg} / \mathrm{mL})$. As has been corroborated with other studies, ziconotide degradation is constant and independent of its concentration (5). Ziconotide has been known to degrade into the following compounds: methionine, ziconotide methionine sulfoxide, acetylziconotide methionine sulfoxide, ziconotide succinimide intermediate, and acetylated ziconotide (5). That being said, sample $E$ was a 3-drug combination (ziconotide [20 $\mathrm{mcg} / \mathrm{mL}$ ], hydromorphone $[7.5 \mathrm{mg} /$ $\mathrm{mL}]$, and baclofen [1000 $\mathrm{mcg} / \mathrm{mL}]$ ), but did not appear to have any changes at the 30-day mark, possibly because of the short time interval. Likewise, sample B (morphine $(10 \mathrm{mg} / \mathrm{mL})$ and bupivicaine $(5 \mathrm{mg} / \mathrm{mL})$ did not seem to have any degradation byproducts. Long-term stability and compatibility of morphine (20 $\mathrm{mg} / \mathrm{mL}$ ) and clonidine $(0.05 \mathrm{mg} / \mathrm{mL})$ admixtures as well as bupivacaine hydrochloride $(7.5 \mathrm{mg} / \mathrm{mL})$ in the SynchroMed infusion system have been reported (6). Moreover, the compatibility of individual analgesics namely morphine, clonidine, and bupivacaine - with the SynchroMed delivery system has also been confirmed $(4,6)$.

Also previously reported is the long-term stability of morphine sulfate in the SynchroMed system. Morphine at room temperature has been reported to be stable for 12 days, 6 weeks, 3 months, and 18 months (7-11). Morphine has also been reported to be stable for months at $32^{\circ} \mathrm{C}$ and for one month at $37^{\circ} \mathrm{C}$ (12). Long-term stability of morphine and similarity in chemical structure between morphine and hydromorphone suggest similar stability properties of aqueous hydromorphone solutions. However, no studies have reported drug combinations of (a) ziconotide and hydromorphone, (b) ziconotide and baclofen, or (c) ziconotide, hydromorphone, and baclofen as reported in this study. Further, it should be noted that the compatibility and stability of drug mixtures varies with different concentrations; it has been noted that higher-concentration mixtures are prone to degradation processes involving intermolecular interactions.

There are a number of limitations in this study.
First, the number of samples studied is fairly limited. However, the goal of this study was merely to see the stability and compatibility of drug mixtures, comparing the drug that was extracted from the pump at the time of the pump refill to the new drug mixture. To that extent, HPLC was used to measure quantitative differences (as noted by obvious differences in the number of peaks) between the samples, not qualitative differences. In order to study qualitative differences, gas chromatography mass spectrometry (GCMS) may be employed to identify different structures. Another limitation is the time frame for pump refill that was used in this study. One of the 5 patients was back within 30 days for the pump refill. Interestingly, this patient had a 3-drug mixture in the intrathecal pump and fortunately no difference was noted in the sample extracted versus the new sample. Most of the other drug combinations were noted to have some degradation/byproducts at 60 or 90 days. It will be valuable to study the safety profile of the drug at different time intervals for pump refill.

\section{CONCLUSION}

While sample A was a single-drug combination, the sample was in the pump for over 3 months; likewise, sample $E$ was a 3-drug combination, but was in the pump for only 30 days. Based on these results, it appears as though (a) when the length of time the drug stays in the intrathecal pump increases or (b) when a combination drug mixture is used in the intrathecal pump (as opposed to a single drug), some drug degradation and/or byproduct formation happens as seen on HPLC. While the reported HPLC data reveals quantitative differences, further qualitative analysis is required for confirmation and possible identification of possible degradation and/or byproducts.

\section{Author Contributions}

Dr. Javed and Huh had full access to all the data in the study and takes responsibility for the integrity of the data and the accuracy of the data analysis. Drs. Javed and Huh designed the study protocol. Dr.(s) Javed and Huh managed the literature searches and summaries of previous related work and wrote the first draft of the manuscript. Dr. (s) Javed and Huh provided revision for intellectual content and final approval of the manuscript. 


\section{REFERENCES}

1. Gerber HR. Intrathecal morphine for chronic benign pain. Best Pract Res Clin Anaesthesiol 2003; 17:429-442.

2. Hassenbusch SJ, Garber J, Buchser E, Du Pen S, Nitescu P. Alternative intrathecal agents for the treatment of pain. Neuromodulation 1999; 2:85-91.

3. Hassenbusch SJ, Portenoy RK, Cousins M, et al. Polyanalgesic Consensus Conference 2003: An update on the management of pain by intraspinal drug delivery - report of an expert panel. J Pain Symptom Manage 2004; 27:540-563.

4. Hildebrand KR, Elsberry DE, Anderson VC. Stability and compatibility of hydromorphone hydrochloride in an implantable infusion system. J Pain Symptom Manage 2001; 22:1042-1047.

5. Bazin C, Poirier AL, Dupoiron D. Influence of $\mathrm{pH}$ and temperature on ziconotide stability in intrathecal analgesic admixtures in implantable pumps and syringes. Int J Pharm 2015; 487:285291.

6. Hildebrand KR, Elsberry DD, Hassenbusch SJ. Stability and compatibility of morphine-clonidine admixtures in an implantable infusion system. J Pain Symptom Manage 2003; 25:464471.
7. Duafala ME, Kleinberg ML, Nacov C, et al. Stability of morphine sulfate in infusion devices and containers for intravenous administration. Am J Hosp Pharm 1990; 47:143-146.

8. Strong ML, Schaaf LJ, Pankaskie MC, Robinson DH. Shelf-lives and factors affecting the stability of morphine sulphate and meperidine (pethidine) hydrochloride in plastic syringes for use in patient-controlled analgesic devices. J Clin Pharm Ther 1994; 19:361-369.

9. Wulf $\mathrm{H}$, Gleim M, Mignat $\mathrm{C}$. The stability of mixtures of morphine hydrochloride, bupivacaine hydrochloride, and clonidine hydrochloride in portable pump reservoirs for the management of chronic pain syndromes. J Pain Symptom Manage 1994; 9:308311.

10. Vermeire A, Remon JP. Stability and compatibility of morphine Int J Pharm 1999; 187:17-51.

11. Essink-Tjebbes CM, Burger DM, Beelen M, Wuis EW, Hekster YA. Long-term stability of morphine and bupivacaine mixture for spinal use. Pharm World Sci 1999; 21:144-146.

12. Roos PJ, Glerum JH, Meilink JW. Stability of morphine hydrochloride in a portable pump reservoir. Pharm Weekbl Sci 1992; $14: 23-26$ 
